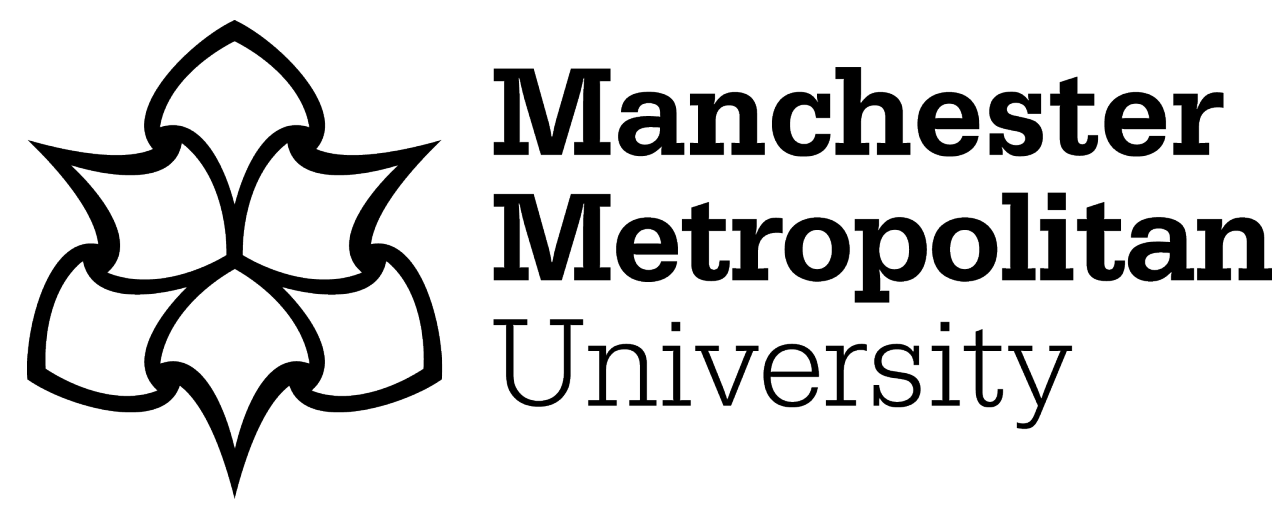

Ndinda, C and Ndhlovu, TP (2016) Attitudes towards foreigners in informal settlements targeted for upgrading in South Africa: A Gendered Perspective. Agenda, 30 (2). ISSN 1013-0950

Downloaded from: https://e-space.mmu.ac.uk/622618/

Version: Accepted Version

Publisher: Taylor \& Francis (Routledge)

DOI: https://doi.org/10.1080/10130950.2016.1212598

Please cite the published version 


\title{
Attitudes towards foreigners in informal settlements targeted for upgrading in South Africa: A gendered perspective
}

\author{
Catherine Ndinda and Tidings P. Ndhlovu
}

\begin{abstract}
Using intersectionality as the organising theoretical framework, this article argues that the attitudes of informal settlement residents towards foreigners are complex, varied and moulded by a multiplicity of factors. Gender intersects in complex ways with social class, space (urban/rural) and political/ideological leanings, among other variables, to shape attitudes. The socially constructed characterisation results in inclusion or exclusion. Indeed, the attitudes held by individuals and groups depend on social and economic positioning as well as the spaces they occupy within the urban/rural/class divides. This serves to explain reticence, denialism and/or justification of violence by different groups in informal settlements, and the distinctions between males and females, and between employers and workers.

Therefore, the argument put forward by this article is that attitudes of informal settlement dwellers (as distinct from slum dwellers) in South Africa towards foreigners, and the resulting unequal outcomes, are explicable from multiple forms of oppression, advantage and disadvantage, and hegemonic power structures. These attitudes are dynamic over time. They are fashioned by interconnections and kinship ties between citizens and foreigners. In addition, contestations over resources and opportunity, as well as notions of identity and citizenship, play a part in how the former view the latter. Crucially, gender intersects with social class and region to form the attitudes that are displayed by citizens towards foreigners in South Africa.
\end{abstract}

\section{keywords}

gender, xenophobia, informal settlements, intersectionality, kinship and identity politics

\section{Introduction}

In May 2008 there was an outbreak of xenophobic violence in South Africa (SA) that left 41 foreigners dead, and 21 citizens were also killed. Over 100000 people were displaced, some seeking shelter in churches and police stations, while others fled the country as looting took place. This violent episode started in Alexandra Township close to Johannesburg, and quickly spread to informal settlements and townships throughout SA (Dodson, 2010; Landau,

Agenda 2016

ISSN 1013-0950 print/ISSN 2158-978X online

(c) 2016 C. Ndinda and T. P. Ndhlovu http://dx.doi.org/10.1080/10130950.2016.1212598
2011). A number of reports attributed the violence to poor service delivery, contestation over resources, foreigners 'stealing' citzens' jobs, and many reasons besides.

These ongoing contestations culminated in the 2015 wave of xenophobic attacks that started in Soweto in January 2015, and resulted in the death of a Somali shopkeeper (Hlubi, 2015). Further disturbances took place in Limpopo province on 5 March 2015. Soon after, on 21 March 2015, reported comments by Zulu King Goodwill Zwelithini

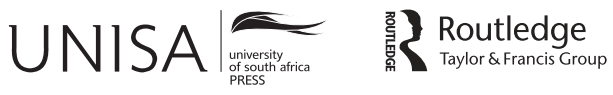
pp. 1-16 
kaBhekuzulu that izigilamkhuba (thugs, those who are given to doing evil) must go back to their countries, lit a tinderbox in KwaZulu-Natal (KZN) (Olifant, 2015). On 8 April 2015 attackers were allegedly heard chanting awahambe amakwerekwere, inkosi ithe awabuyele emuva (the king has said that foreigners must go back to their countries; amakwerekwere being a derogatory term for foreigners). Foreigners' shops were torched and looted, leading to the displacement of over 2000 foreign nationals from countries such as Burundi, Democratic Republic of Congo, Ethiopia, Malawi, Mozambique, Somalia, Tanzania and Zimbabwe. The violent orgy soon spread to Gauteng province.

While informal settelements in SA are characterised by poor or non-existent water and sanitation facilities, overcrowding, unemployment, poverty, non-permanent structures and lack of tenure, it is worth noting that they are not necessarily synonymous with slums. Indeed, Rao (2006) argues that we must guard against the liberal modernist dichomies between slums and formal settlements in the city, that is, the socially constructed 'urban divide' that is typical of UN Habitat (2010:6) analyses (see also Amin and Thrift, 2002; Cameron and Ndhlovu, 2001; Davis 2004). While the upgrading of informal settlements programme (UISP) in SA is also premised on their perceived "illegality and informality; inappropriate locations; restricted public and private sector investment; poverty and vulnerability; and social stress" (Department of Human Settlements [DHS], 2009:16), it is noteworthy that there may also be cases where murderous behaviour is not a raison d'etre of slums.

In addition, Landau (2011) notes that while the State machinery seeks to "exclude and remove unwanted outsiders", implementation of this policy is discretionary. At various points the police will ignore the existence of "outsiders", and even develop "informal protection rackets" that facilitate their continued stay in informal settlements (see also Nyamnjoh, 2006:2007).

In SA understanding difference as complex and contingent is further complicated by the tendency to refer to African immigrants as 'foreigners', while white immigrants from other continents are rarely, if ever, referred to in similar terms.
The latter are often labelled as expatriates, and therefore little attention is paid to their business operations in the central business districts of cities.

It is against this background that many studies have sought to explain the root causes of xenophobic violence that took place in SA in 2008 and 2015. These range from 'economic' and 'social' reasons to denials about its existence. The latter view, which we describe as denialism, has been a dominant tone projected by the leadership of the African National Congress (ANC). For instance, former President Thabo Mbeki described xenophobia as criminal acts by a rogue minority. In his view, this behaviour could arguably be amended by improving people's knowledge about their history, geography, cultures and languages, and thus creating an environment that is conducive to the project of an African Renaissance (Dodson, 2010:7-8).

Some scholars have concentrated on identity politics as explanations of xenophobic violence (Landau, 2008, 2011; Pillay, 2008; Sharp, 2008). Given the laager mentality in the racial hierarchical system of apartheid, a "fear of the unknown" (Hobsbawm, 1992) or rejection of foreigners or 'otherness' projects itself in attitudes of superiority (see also Adjai and Lazaridis, 2013; Dodson, 2010:6-7; Neocosmos, 2008). The narrative about the 'others', as Ahmed (2014) observes, refers to "illegal immigrants" and "bogus asylum seekers" that threaten "the true recipient[s] of national benefits". White settlers in SA cultivated notions of superiority to other races, and even went so far as to depict the rest of Africa ('up North') as inferior to South Africans. This colonial and apartheid ideology is arguably still embedded in many people's minds, so that some black people even hate/d themselves and despise/d 'other' ('foreign') blacks more than they detest/ed white oppressors, yearning to be like abelungu or ogamla (white people who were/are associated with wealth and prosperity). This is probably why some 'coloureds' (those of mixed parentage) regard themselves as superior to blacks.

Thus, "an irrational fear for outsiders" (Landau et al, 2005) or "the fear or hatred of foreigners or strangers" (Solomon and Kosaki, 2013) manifests itself in all manner of discrimination and "scapegoating" (Ibid.; 
Bond et al, 2011; Crush and Ramachandran, 2014; Harris, 2002; Hendrickse, 2009; Morris, 1998; Tshikereke, 1999). It is contended that competition for resources is predicated upon indigeneity (i.e. that access to resources depend on whether one is an indigenous South African). The "notion of South Africa's apartness" and even "rejection of African identity", as Msimang (2014) notes, is not only born out of the 1937 Aliens Act, but also continues to perpetuate notions of insularity and exclusion. Other studies highlight the leadership deficit. In other words, that resentment of foreigners is utilised by unscrupulous community leaders to whip up patriotic and nationalistic feelings.

Given these various approaches that have been deployed in explicating xenophobic violence in SA, this article adds another dimension of place (informal settlements) in exploring how gender intersects with a range of variables in shaping attitudes towards foreigners. It argues that xenophobic violence in SA is not limited to the large-scale outbreaks that have been widely reported in the media from time to time (2008; 2015); the violence is both subtle and brutal; it occurs in both public and private spaces; it is perpetrated by both groups and individuals.

While the physical violence is visible enough to be captured in photographs and quantified, other forms of xenophobia (which are equally if not more bruising and violent in their impact) remain unaddressed and, in fact, may have become normalised. Xenophobic attitudes and violence cut across gender, race and class, and therefore the focus on informal settlements should not be construed to imply that such spaces are the epicentre of xenophobia in SA. Informal settlements happen to be the places where such violence has tended to be more widely reported.

This article recognises the complexities of shared and lived experiences, as well as the power structures that shape attitudes towards foreigners. Focus is placed on the "interconnected and constitutive nature of multiple forms of oppression (and privilege)" (Bastia, 2014:238) rather than binary identities. The analysis in this article suggests that citizens represent a privileged group, whereas foreigners, by virtue of being non-citizens, represent a vulnerable, oppressed group. Yet vulnerability in SA is mediated by factors such as race and class.

While xenophobic violence has largely been directed at African foreigners, there have been few if any reports of similar violence directed at other groups. Whereas xenophobic violence might occur anywhere, including in middle class suburbs, much of the reporting tends to focus on poor, working class neighbourhoods. It is for this reason that an intersectional approach has been adopted to ensure that we do not 'conflate group differences' in a way that prevents us from seeing that violence is shaped by many factors, such as race, gender and class (Crenshaw, 1989, 1991; see also Collins, 1998, 2000).

For Crenshaw, it was important to dispel the myth that women in the United States of America (USA) were homogenous; in other words, to challenge the legal implications of assuming that women's lives were the same. This line of enquiry has taken many forms subsequently, for example, examination of multiple burdens. Our investigation of attitudes towards foreigners in SA is informed by what Collins (2000:42,73) describes as the "interlocking oppression" of race, class, gender and ethnicity; that is, the "interlocking matrix of domination" (see also Anthias, 2012; Bastia, 2014; Crenshaw, 1989, 1991; Davis, 2008; Ndhlovu, 2012, forthcoming 2016b; Ndhlovu and Spring, 2009; Ndinda and Okeke-Uzodike, 2012; Shahrokh, 2015; Walby, 2007).

Intersectionality seeks to integrate gender, class, race, ethnicity and other factors besides. It examines how power structures, advantage and disadvantage, and the way in which the projection of particular groups of people (migrants, for example) by the State intersect in people's lives to give meaning to their everyday experiences. The dynamics of inclusion and exclusion are related to gender and citizenship (acquisition and protection of rights and benefits), while stereotyping "essentializes and exaggerates perceived cultural differences and thus gives rise to prejudice and antagonism" (Dodson, 2010:6; see also Nyamnjoh, 2006, 2007).

Thus intersectionality not only makes sense of how relations between 'citizens' and foreigners are expressed or described, negotiated and contested, but also 
illuminates our understanding of disputed spaces within power relations in informal settlements, and how identities are constructed in post-apartheid SA. The focus is on the complex intersections with racial, gender and migrant identities in the South African context. Not only is intersectionality focused on privilege and oppression and how difference (the 'other') can lead to exclusion but, more crucially, "gender, race and class (among others) are understood as being relations of power that lead to unequal outcomes" (Bastia, 2014:244).

Economic, political, social and cultural lenses provide insight into how notions of difference and manifest violence are constructed in informal settlements. The focus on attitudes of informal dwellers towards foreigners needs to be understood as one aspect of a larger study that sought to collect baseline data on informal settlements targeted for upgrading (Ndinda et al, 2016). Thus, the purpose of the article is to illustrate the varying, dynamic and complex attitudes and argue that these need to be understood in order to draw policy implications towards xenophobia.

This article begins by explaining the methodology deployed in data collection and the analysis utilised. The intersectionality approach is interwoven with and interpretive of the thematic analysis of the findings, and the article ends with a recapitulation of key points arising from the broad analysis of the attitudes of informal settlement residents towards foreigners in SA.

\section{The focus is on the complex intersections with racial, gender and migrant identities in the South African context}

\section{Methods}

The findings reported in this paper are based on a baseline assessment of sampled informal settlements that were targeted for upgrading (Ndinda et al, 2016). These settlements were defined as those listed in the plans of municipalities and metros that were due for improvement from 2015 to the 2019 financial year.

Purposive sampling was used to obtain lists of targeted settlements from municipalities, and stratified random sampling was applied to obtain a national representative sample. The informal settlements were stratified into provinces, and randomly selected for each strata (province) using the Statistical Package for Social Science (SPSS) software. The sample size was a function of the number of settlements targeted per province rather than the total number of informal settlements in any province.

The total number of informal settlements targeted for upgrading was 1185 ( $n=1$ 185) and a $10 \%$ sample size equated to 119 informal settlements $(n=119)$. A random sample of 45 households was selected from each of the 119 informal settlements targeted for upgrading, resulting in a total sample of 5355 households. An additional 45 households were also sampled from each of the 11 mining areas ( $\mathrm{N}=495$ households), resulting in a targeted sample of 5850. Due to temporal and financial constraints the total number of settlements visited was 78 informal settlements and 3330 households. Out of the 78 settlements, three were from the mining towns and the rest were from the main sample. Among 3330 households visited, 128 were from the three mining towns. The valid number of households was $3088(93 \%)$ while $242 \quad(7 \%)$ were invalid, meaning that these no longer existed or the selected sites were occupied by churches or business premises. Among the 3088 valid households, $2493(81.0 \%)$ were interviewed while 108 (3.0\%) were refusals. The statistics reported in this article are based on the weighted data from the main sample (2380 households), and excludes households (113) in the mining towns. Given the large number of informal settlements, focus group discussions (FGDs) were conducted in selected rural and urban municipalities in order to sensitively tease out the salient issues. The FGDs were convened to discuss the status of informal settlements in general, and attitudes towards foreigners were among the topics discussed (in July-August 2015) following the 2015 xenophobic attacks (April-May 2015) in KZN.

Through purposive sampling areas with large metros as well as rural towns with informal settlements were identified for FGDs. Participants were invited to focus groups following meetings with ward committees where the purpose of the study and its objectives were explained. Once the 


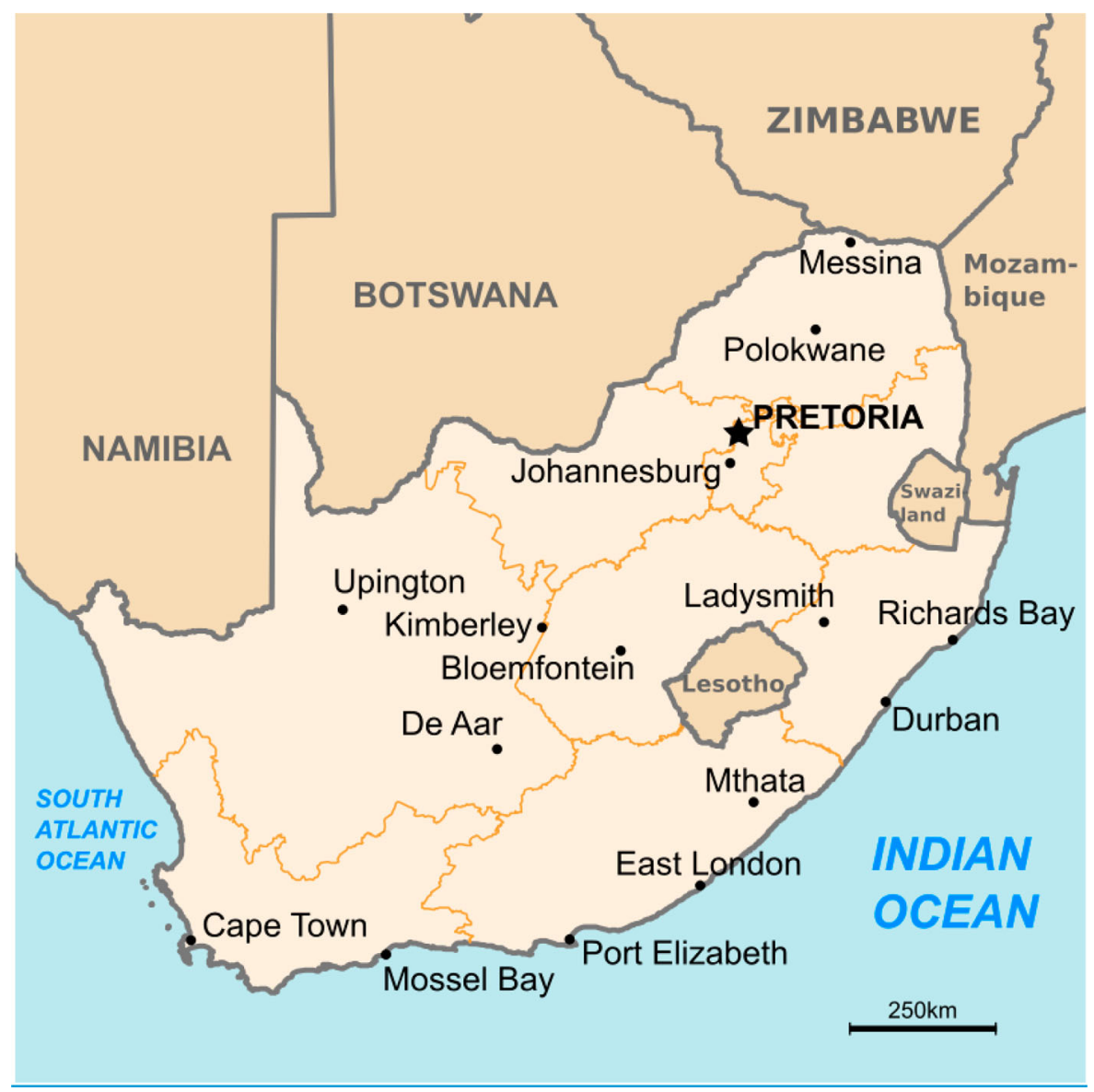

Map of South Africa and its African neighbours, between and within which there is much movement of people.

ward committees had granted permission to conduct the study in the settlements, committee members assisted in informing their members about the focus groups and the eligibility criteria, that included that participants be aged 18 years and above. Study teams that administered household questionnaires also invited members to the focus groups.

Invited participants who arrived at the FGDs were taken through the study information in line with ethical principles (Ndinda et al, 2016). Their acceptance to participate in and recording of FGDs was required, and only participants who consented participated in FGDs. To ensure confidentiality and protection of study participants, each discussant was allocated a pseudonym that was used to address them throughout the discussion.
In total 23 homogenous FGDs (spread across the nine provinces) were conducted, 11 with just males and 12 with just females. Each focus group comprised 6-12 discussants. In total 171 discussants participated in focus groups in selected informal settlements in all nine provinces. The FGDs were moderated by facilitators who posed openended questions and probed the participants, and a note-taker ensured that the electronic recorder was functioning. Taking a cue from experience in previous studies (Ndinda et al, 2007a, 2007b, 2008), this twin strategy guaranteed that a record of the discussion would be available even if the recorder malfunctioned. The notes also helped in identifying participants by their pseudonyms when transcription took place.

The FGD recordings were transcribed verbatim in the local language then 
translated into English. It is noteworthy that there are terms whose meanings are not as easy to convey in English as in the original language (for example, hayyi, hawu, eish, etc.). The textual data were subjected to thematic analysis, that is, "an approach ... which identifies and categorises themes in texts such as interview or focus group transcripts, or documents" (Searle, 2012:599). Thematic analysis in this study entailed the researchers getting immersed in the data to ensure sensitivity. To the extent that questions had been prepared and issues for exploration identified prior to the fieldwork, the line-by-line coding of textual data was thus deductive. Yet immersion in the data revealed more complex attitudes than reflected in the literature or the FGD questions. Inductive coding was used to explore the attitudes identified in greater detail.

\section{the concept of foreignness in SA is complex} and contested, and the qualitative findings from this study delve into the definition of who is and is not a foreigner

Textual data analysis that took place can be broadly characterised as coding, categorisation and theme identification (Rivas, 2012). Given the deductive and inductive methods referred to above, in vivo coding was used to identify the codes that were emerging from the data. The codes were categorised according to emerging dominant ideas from the textual data, and interrater reliability helped in comparing the themes identified. What emerged were themes that were similar, while differences in analysis of the data were accounted for by the emphasis placed on some themes and selection of extracts to support the dominant themes.

\section{'Them' versus 'Us': Identity and the politics of belonging}

Male participant in Diepsloot, Gauteng: “... they [foreigners] are accused of criminal activities, trafficking, raping, you name it. If you [ask], who is a foreigner, - - - [informal settlement dwellers] would mention, Zimbabwean and Mozambiqu [an]. Those from Swaziland, Botswana and Lesotho are not foreigners, because they are very close to us, that is the problem."
As noted, the concept of foreignness in $\mathrm{SA}$ is complex and contested, and the qualitative findings from this study delve into the definition of who is and is not a foreigner. The term 'foreigner' generally refers to non-citizens in any context, and certainly in SA's policies on immigration. However, the common use of the term by the public has taken on a meaning of its own, and has come to denote non-citizens from African countries.

Consistent with the common everyday use of the term foreigner, study participants went to great lengths to distinguish whom they consider foreigners or locals/citizens. Community perspectives suggest that Africans, that is, black people, are considered to be foreigners, particularly those from Zimbabwe and Mozambique. However, people from Botswana, Lesotho and Swaziland are exempt from this categorisation because, so the reasoning goes, their countries are geographically close to SA. Yet the excluded countries of Zimbabwe and Mozambique also border SA.

One possible explanation for this conundrum lies in the languages spoken in Swaziland (siSwati), Lesotho (siSotho) and Bostwana (siTswana), which are similar to those spoken in SA - isiZulu, isiXhosa and siSotho (Southern and Pedi). Using the same logic, the Ndebele language of Southern Zimbabwe is an Nguni language that is practically the same as the isiZulu that is spoken especially in KZN and Gauteng. In fact, whereas the Ndebele are direct descendants of the Zulu general Mzilikazi KaMashobana, it remains a paradox why they are categorised as foreigners. Similarly, the Shangani (abaseGaza) from Mozambique are descendants of the Zulu general Soshangane (Ndhlovu, 2016a).

Arguably informal settlement dwellers' definitions of national/foreigner categories, their distinctions between 'local foreigners' and 'foreign, foreigners', are arbitrary and reflect how they make sense of and attempt to interpret the complex and seemingly unfathomable geopolitical divides within the region.

While there is ambiguity in labelling noncitizens, the qualitative findings provide a glimpse of the self-characterisation that intersects with entrenched hegemonic power, prejudice, stereotypes and projection 
of certain groups in society that result in either inclusion or exclusion. This is reflected in the language and tone used to describe the relationship between informal settlement residents and foreign nationals. For example, in areas where there are favourable attitudes towards foreigners, terms used to describe the relationship are often complimentary: "Foreigners are people just like us. As a result, we get along with our foreigners" (Joe Slovo, Eastern Cape, female); "we respect them ... treat them as equal to us" (Mafikeng, North West, female); "They are good" (Free State Unit 3, female); "They are our brothers and some of them are now even our brothersin-law" (Orlando, Gauteng, male).

In exploring identities, Alcoff (2006) juxtaposes real identities (the visible such as race/ethnicity and sex/gender) and perceived or imagined identities (the invisible such as class or learned/habitual ability regarding race). Whereas racialised or ethnical differences, for example, can be manipulated by unscrupulous leaders to justify conformism and corruption, it is contended that acknowledgement of differences is important in correctly identifying "real commonalities and shared interests". Alcoff goes further to note that "visible manifestation of racial and gendered identities" may obscure "visible markers" that are used to determine one's race and gender. Clearly, this leaves room for interpretation and the uncovering of the hidden. Thus, when analysing culture, ethnicity and identity, attention must be paid to the specific context, as well as the universal. In addition, we must take account of dynamic changes in culture and identity, and the way they interact and are transformed by inequalities in "wealth and resources". According to Alcoff (2006), "gender as positionality" helps to explicate women's identity within a social or economic system of production.

\section{Discourses of kinship and common humanity and identity politics}

In line with Alcoff's (2006) argument, Ahmed (2014) examines race, sex and gender as constitutive processes so that sexual difference, through kinship, actually produces a sense that some people belong and others do not. She also refers to narratives about groups of people identifying themselves as injured parties and thus identifying the 'other' (foreigners, for example) as shattering the unity of the nation (see also Mupotsa, 2011). It is for these reasons, as will be discussed in the following sections, that the Government is often denoted as 'a soft touch' and calls are made for tightening immigration and asylum rules and regulations. In other words, kinship is couched within nationalistic or patriotic contexts: “The use of metaphors of 'softness' and 'hardness' shows us how emotions become attributes of collectives, which get constructed as 'being' through 'feeling'. Such attributes are of course gendered: the soft national body is a feminised body, which is ... 'invaded' by others" (Ahmed, 2014:2).

Of course, this narrative, as Ahmed (2014) observes, is interrogated by social and economic factors, and can thus be undermined and challenged. For example, in SA there are cases where kinship or affinity between citizens and foreigners is acknowledged and warm relations are displayed. In such circumstances, terms of endearment and camaraderie are often used: "good", "giving", "they don't bother anyone", "people just like us", "skilled", "kind", "our brothers", "our brothers-inlaw", "our children", “our grandchildren", "we are all Africans".

Kinship and common humanity was deliberated upon in six male and eight female focus groups. Male participants in Limpopo contended that foreigners in their communities were just like them and they treated them similarly to everyone. Moreover, they socialised with the foreigners: "we drink together" (male participant 4, Roosenkal). In the Northern Cape the relationship between locals and foreigners was rather distant and mainly based on transactions. Local people bought supplies from immigrant shops, but they were not friends. When pressed, participants still insisted that "We're all God's people" (male participant 7, Promised Land). Similar detached views were expressed in a female focus group.

It is notable that generally male participants described the relationship between local people and foreigners in utilitarian terms: "we learn from them", "They are not really our friends, we just buy from them" (participant 7, Northern Cape 
Promised Land). This suggests that male informal dwellers viewed foreigners primarily in functional terms, while a rural female focus group expressed attitudes towards foreigners in terms of common humanity. In other words, while male participants saw the relationship as chiefly one of exchange, women referred to it as connectedness: "we love them" (participant 1, Madelakufa, Gauteng) - not literally, but denoting that informal dwellers were not hostile to foreigners and indeed looked out for them. These views were expressed by female participants in both urban (Gauteng) and rural (Limpopo) settlements. Informal dwellers also recognised that they all had the same origins, and that people are as much human as spiritual.

While informal settlements have been considered to be spaces of exclusion, they can be spaces of inclusion where the 'other' that is excluded from the mainstream economy finds a shared identity

In both male and female focus groups (rural and urban), kinship was a recurring theme. It was mentioned in 14 focus groups (six male and eight female). In four male focus groups kinship ties were allied to immigrant men. For the male participants in both urban and rural settlements, malegendered terms were used to describe foreigners, and the relationship to them was defined in patrilineal terms (brothers from another mother; brothers-in-law, or simply brothers). While no male focus group mentioned immigrant women as part of their affiliated kin, a rural focus group (KZN) did refer to their relatedness to foreigners. Apart from this exception, foreigners were depicted predominantly as male, perhaps because of the portrayal of immigrant women as muted, hapless and helpless victims of xenophobic violence. Moreover, the voices of foreigners in the media are predominantly those of powerful urban males.

Using intersectionality to explore kinship helps to explicate inclusion and exclusion as socially constructed notions that are expressed in terms of gender, and can indeed shape our understanding of citizenship. As indicated earlier, foreign men more than women were often considered 'kin', due to their 'visible' association with local women. Nevertheless, in SA more was also read into these liaisons. Marriages between local women and immigrant men are viewed with suspicion, and associated with securing citizenship. This suggests that locals are also prone to jealously guarding their "rights and benefits [of citizenship] against perceived threats of undermining or usurpation by noncitizens" (Dodson, 2010:6), although there is "confusion about who is legally entitled to live and work in South Africa" (Ibid.).

The concept of a broader, common African identity that encompasses and defines both citizens and foreigners was expressed within an urban male FGD in Orlando, Gauteng, perhaps reflecting urban men's more vocal offerings in political deliberations: "We are all Africans".

Despite immanent tensions, recognition of close kinship implies a shared past, shared values and a shared destiny. Similar ideas were voiced by rural men in KZN. While informal settlements have been considered to be spaces of exclusion, they can be spaces of inclusion where the 'other' that is excluded from the mainstream economy finds a shared identity, not just based on (possible) ethnicity or nationality, but also on the shared experiences of living in spaces of exclusion. Ironically the fraying at the edges has happened in a region where immigration has been an everpresent feature since colonialisation and Shaka's "Great scattering" or umfecane (Ndhlovu, 2016a; see also Amisi, 2009; Hendrickse, 2009:2-5; Reitzes, 2009). In recent times, while SA has received migrants from neighbouring countries, especially in the wake of political and economic turmoil in the Democratic Republic of Congo and Zimbabwe, other countries such as the United Kingdom, USA and Australia have also taken South African (predominantly white) migrants (McConnell, 2009:35-37).

Notwithstanding mutual stereotyping that gives rise to hostility, prejudice and contestation over universal rights and benefits (Dodson, 2010), a common African identity was a recurring theme - 'Africans without borders', so to speak, or to borrow a phrase from Isidingo (a local television soapie) - "brothers from another mother". Notions of kinship, a common humanity and a shared African identity were held by 


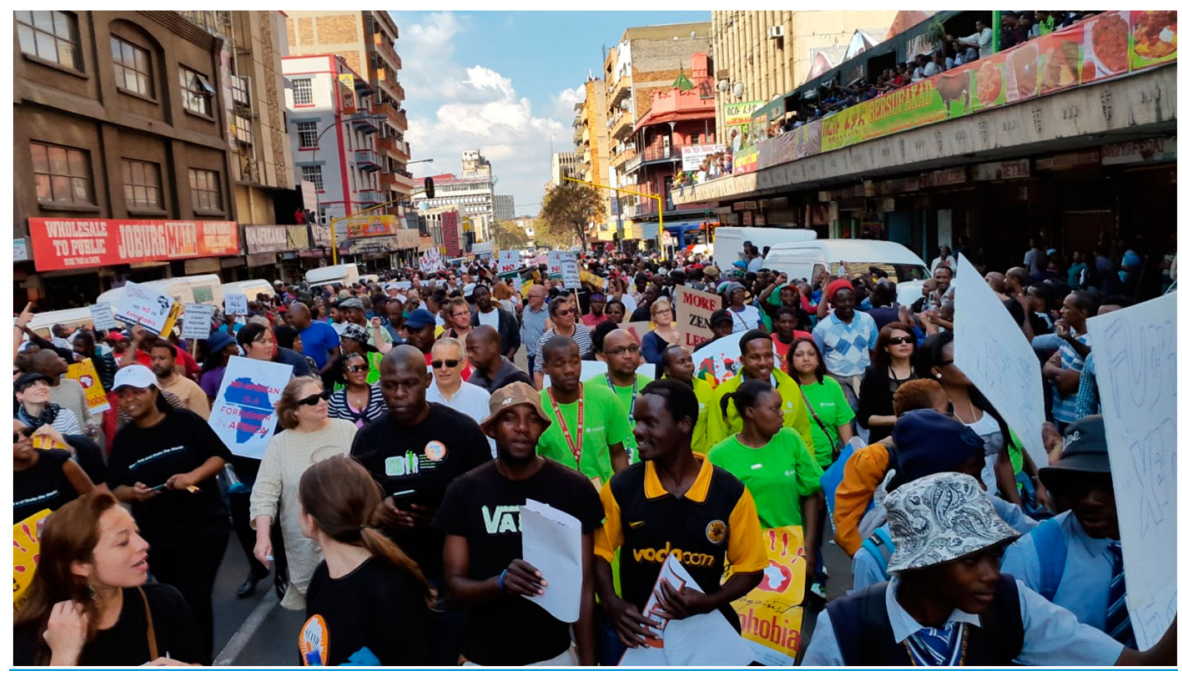

March against Xenophobia, Johannesburg, 23 April 2015. PHOTO: Creative Commons.

both male and female discussants living in both urban and rural informal settlements.

\section{“They are taking our jobs and women": African foreigners as a threat}

Given this conception of humanity and identity, it is paradoxical that foreigners should be accused of "stealing" the jobs of nationals. This refers to foreigners' purported willingness to take lower-paid jobs; unfair competition in business; their perceived better living standards while citizens live in squalor and experience high levels of unemployment; and their status as 'economic migrants' rather than refugees fleeing brutal regimes. As far as foreigners "taking our women", we shall interweave our findings with the implications of the crisis of social reproduction (Hickel, 2014) on SA.

The most dominant theme that emerged from FGDs was how informal dwellers understood the contribution of foreigners, specifically to their communities and SA in general. Twenty focus groups commented (eight male, 12 female). As indicated earlier, male focus groups tended to concentrate on functional aspects such as the skills of foreigners. In addition, local entrepreneurs felt threatened by competition from foreigners, fearing for their own survival.
For their part, rural male participants in Limpopo and KZN regarded foreigners' skills as a boon for local communities, especially if they could tap into these skills. Artisan skills, for example, could enable them to generate income. Paradoxically, a large proportion of skilled (migrant) professionals are unable to secure employment at a time when there are acute shortages of skilled workers in SA (McConnell, 2009:37).

This begs the question why, if locals saw benefits in co-operating with foreigners, they nevertheless attacked and looted the latter's shops. Urban male participants (Gauteng) were at a loss to explain this paradox. Like the denialist view in the ANC, rural male participants (Mpumalanga) cited the unemployed as more likely to attack immigrant shops, although there had been no reports of violence during the 2015 xenophobic attacks in their rural town.

In the North-West, Free State and Northern Cape male participants identified highly discounted prices of goods at immigrant shops as beneficial to local communities. Reticence and ambiguity from some participants should be couched within the context of high levels of poverty where survival is a daily grind for many households (Ndinda et al, 2016). Our household survey also revealed power and dependent relations. Informal dwellers borrowed money, especially from immigrant shop owners, 
not for improving their homes but for meeting basic needs such as food and school fees. Urban female participants in the Western Cape also argued that accessing groceries from immigrant shops on credit saved their households from hunger and starvation.

Overall, while the male focus groups underscored the importance of immigrant enterprises in the informal settlements, female focus groups in KZN, Gauteng, Free State and the North West tended to emphasise the implications of relatively low prices in immigrant shops for local businesses. They contended that cut-throat competition manifested itself in foreigners "stealing" customers from local entrepreneurs, eventually resulting in bankruptcies. Besides, foreigners were likely to patronise only fellow foreigners' shops. There was also a perception that immigrant traders were reluctant to employ local community members, thus preventing redistribution of profits.

Discussions concerning employment also cropped up without prompting in male focus groups. In the platinum belt (NorthWest) male participants viewed foreigners as primarily economic migrants and were happy to work with them, although female groups saw their presence as limiting job opportunities. For their part, male participants in the Free State concurred with the 'economic migrant' argument, adding that foreigners were not necessarily looking for permanent citizenship.

A more nuanced argument was articulated by female participants in KZN. Urban female participants argued that failure of foreigners to join trade unions and participate in strikes undermined the working class struggle for higher wages and better working conditions. Female participants in Mpumalanga and Gauteng argued along the same lines, supporting the contention that acceptance of low wages by foreigners led to redundancies of locals. Interestingly, only one male group (rural KZN) expressed this viewpoint.

While on the surface women appeared to be more hostile than men regarding employment of foreigners, their sophisticated class analysis raised questions for employers: How could the widening wage gap between men and women be addressed?
How were 'decent wages' (to use the International Labour Organization concept) or a 'living wage' for both local and immigrant workers to be instituted? Notwithstanding this, there was consensus by males and females that foreigners were hardworking and single-minded in their pursuit of betterment. In discussions of employment, gender intersected closely with region.

Another concern was how immigrant men in particular were seen to be interacting with local women. The responses of male participants in the North-West and KZN were ambiguous and/or contradictory. While they implied that violence took place elsewhere, male participants in urban North-West (Kanana) blamed the victims:

"The attacks are caused by their behaviours, and they did [a] lot of bad things and someone once killed a child in Johannesburg and another one in Free State, you see; and others are sleeping with our children too, there are lot of things that they do. So I came to the [conclusion] that [the] community cannot take it anymore and also because our government is not taking any steps ... you won't be happy when they tell you that someone slept with our 12 years old kid. That led to these attacks."

In four female FGDs (Mpumalanga - 1, KZN - 2, Western Cape - 1) where there was evidence that violence had actually taken place, participants attempted to justify the attacks on foreigners by local men as because "foreigners are taking their women".

These views may be explained within a historical context, that is, the apartheid system of racial politics and stratification. The construction of a 'neo-liberal man' one who is a breadwinner, has a steady job and resides in townships (elokishini) - was designed to pre-empt black dissent (Hickel, 2014:106-107; Landau et al, 2005:8-9; Ndhlovu, 2016a; Ndhlovu and Khalema, 2015; Ndinda and Okeke-Uzodike, 2012; Reitzes, 2009; Solomon and Kosaka, 2013:10-14). Black men had to aspire to this ideal while being migrants in white-controlled cities, mining towns and farms. However, as the contradictory process of capital accumulation was bedevilled by crises and the tendency of the rate of profit 
to fall, not only did this result in high and increasing levels of unemployment, but the neo-liberal idyllic family was also shattered. Disintegration of the neo-liberal man began to threaten social reproduction as the unemployed were unable to meet their cultural obligations of paying ilobola (bride price) and this in turn led to a fall in the proportion of married people from $65-66 \%$ in 1960 to $33 \%$ currently (Hickel, 2014:107).

These developments, among others, have arguably influenced attitudes towards foreigners. Despite $50 \%$ of foreigners being self-employed and providing employment for about $67 \%$ of South Africans, while also equipped with better skills and drawing relatively little from the public purse (Hickel, 2014:115,123; Landau et al, 2005:6-8), the locals sometimes blame foreigners for their economic and social misfortunes (amashwa). Rights and benefits of full citizenship were only secured in 1994 with Mandela's ANC government. With recurring financial and economic crises, locals may thus project their frustrations concerning unemployment and poverty on foreigners.

The threat to livelihoods and questioning of 'neo-liberal man's' place in society, especially in the context of the emasculated breadwinner attracting social ridicule from womenfolk in the community, may at different flash-points lead to lashing out at shadowy foreigners who are perceived to be merrily building up isheleshe (unexplained wealth). Local citizens may seem to wait interminably for jobs, while foreigners appear to accumulate wealth without the added social responsibility of a family or going through the traditional rituals of paying 'damages' (imhlawulo) in the case of children born out of wedlock. It is worth noting that for the young generation (the 'born frees') there is no institutional memory of the crucial role played by African countries in the liberation of SA.

While the complex interlinking of race, gender and ethnicity can begin to give us a better understanding of why xenophobic violence occurred, we must also guard against "depoliticizing intersectionality and using it merely as a tick-boxing exercise to show that the 'relevant' differences have been taken into account" (Bastia, 2014:246). Some of the reasons for the xenophobic violence that erupted in 2015 can be gleaned from these economic and social struggles.

\section{Violence towards foreigners}

The picture that emerges from these FGDs is a complex one, and painted on a historical, colonial/apartheid canvas. Gender, class, race and ethnicity are interwoven rather than projected as "separate essentialist categories" (Bastia, 2014:238). Analysis of the general and the specific suggests that negotiation of spaces that is interrogated by entrenched hegemonic power leads to either inclusion or exclusion, and could be tragic and traumatic - as the events of the 2008 and 2015 xenophobic attacks showed. Put in other words, what this demonstrates is that violence is not an unrelated outcome of processes of making some people unfamiliar or different - it is constitutive to the work of making difference.

It is in this light that responses of participants in various focus groups to violence that occurred in 2015 were of crucial significance. Of 18 focus groups that responded to the question of violence towards foreigners, nine comprised men and nine women. All of the male focus groups, be they rural or urban in Limpopo, Mpumalanga, Gauteng, Eastern Cape, Western Cape and the North-West, adopted a denialist stance about violence in their own settlements. On further probing, urban male participants in Gauteng were adamant that violence could not be condoned, adding (as in Mbeki's contention) that only criminals were involved in these incidents. This view was held by male participants in NorthWest, while those in the Free State emphasised good relationships with foreigners. Rural participants (Mpumalanga) were also emphatic that there had been no hostility or violence towards foreigners in their areas. As indicated above, denialism was an attempt to circumvent the link between projection or acknowledge of difference with 'subjects' of violence, while identifying a small group of 'visible' criminals as the sole culprits.

violence is not an unrelated outcome of processes of making some people unfamiliar or different - it is constitutive to the work of making difference

Whereas (in KZN) rural male participants insisted that they lived in harmony with foreigners and that violence did not take 
place in their areas, they still associated them with foreigners' alleged criminality and illegal activities. "I'll put it like this - - because we have not seen community members saying that they do not want them because they are 'this'; I can say that that happened in other places, that has not happened here. But we are still living with them." (male participant 4, Faireighs, KZN). Yet the underlying hostility was palpable as some participants laid down conditions for living with foreigners in their communities: "If they behave themselves there is no problem because we even get assistance from them. If someone wants to start selling anything, they [must] hire South Africans and they are then able to assist" (male participant 1,_Poortjie, KZN).

On the other hand, responses from female FGDs were mixed. Of the 10 female FGDs that responded to the enquiry, five (Gauteng, Free State, Eastern Cape, North-West) were categorical that there had been no violence in their communities. One was non-committal (rural Limpopo), and its participants drew from notions of common humanity: "We feel pity for them, we don't know if we could say they must leave or go, they are human beings just like us" (particpuant 1, Vaalwater FGD). However, there was still an undercurrent of hostility and resentment towards foreigners. The participants in urban KZN added that foreigners had stolen jobs from locals and accepted low wages, thus putting locals out of business and employment, resulting in a snowball effect of violence. In deep rural KZN (Zamani), a female participant observed:

\begin{abstract}
“What created these problems ... er, it's us. As it started in Johannesburg, where a boy was beaten up because he had stolen, they killed him and then they were beaten and then it caught on in Durban so much so that we saw in the news that the foreigners were getting beaten up indeed. So even here [violence has taken place], but fortunately when they were asked to stop, they were able to do so quickly. But there were some who got the beatings but not like in Durban because in Durban they were even taken to Chatsworth."
\end{abstract}

What can also be read into these narratives is the historical and colonial legacy of violence that has become a way of life in resolving challenges and conflict in SA. Misago (2009) adds that service delivery failures, inadequate institutional structures and a void in community leadership may also be catalysts that trigger violence. Allied and linked with the contention that violence is constitutive of difference-making processes/prejudice is the context or structuring conditions in which it takes place. For example, in all the informal settlements sampled, $44.7 \%$ of households reported that service delivery protests had resulted in violence, while $48.1 \%$ (Ndinda et al, 2016) reported that there had been no violence. Housing was cited by most households $(60 \%)$ as the main reason for service delivery protests, with the majority of the cases reported in KZN (86.5\%), followed by Limpopo (81.3\%) and Eastern Cape (79.1\%). Protests were also sparked by lack of water and electricity.

Using intersectionality to explicate xenophobic violence, the findings suggest that silence and denialist positions of both men and women in informal settlements exist alongside underlying hostility towards foreigners. Moreover, hostility to foreigners might simultaneously also express 'attitudes' about race and gender. Indeed, while there was hesitance in openly acknowledging violence directed towards foreigners in their communities, informal settlement dwellers proffered other reasons (depending on region and class) for violence predicated on gender and power relations. These included threats to local businesses and jobs, associated issues of class struggle, the extent of recognition of kinship and commonality, and alleged slack immigration controls that are associated with 'othering' and increases in criminality by foreigners.

\section{Legality/illegality discourse}

Despite crimes committed by foreigners constituting only $2-7 \%$ of the total, largely confined to arrests for illegal immigration, the rhetoric of 'illegal foreigners' is a commonly accepted way of describing African foreigners in SA. The media is a major culprit in perpetuating and entrenching such myths and misconceptions, depicting Africans as 'corrupt', 'illegal' and sources of 'cheap labour', thus pitting locals against foreigners. 
In the course of our investigation legality/ illegality issues emerged in both male and female FGDs in urban and rural areas. The question arose without instigation in both male (four) and female (three) focus groups, both urban and rural.

Male discussants were concerned that after committing crimes illegal foreigners could not be traced or identified by the authorities. They were of the view that illegal foreigners "change[ed] [their] names daily" (Mohlakaneng male participant). Participants in Limpopo went further in suggesting that foreigners should only be allowed to stay in the country if they already had legal documents/permits. Similarly, male participants in North-West advocated for stricter immigration laws to stem the perceived flow of traffic. The question that arises is why male participants in the North-West expressed such strong views, when both these provinces are within the 'platinum belt' that makes them attractive to both locals and foreigners seeking employment opportunities in the platinum mines. Despite having maintained that they worked well with foreigners, participants in rural KZN were nonetheless hawkish in their insistence that foreigners without permits should not be allowed to enter the country.

For their part, female FGD participants approached these concerns from a different angle. In Mpumalanga they associated foreign men's proposed marriages with local women as a ruse for obtaining full citizenship. Given their apparent hostility to immigrant labour, as discussed earlier, it was equally surprising that female participants in KZN advocated for assistance to foreigners without correct documentation to enable them to normalise their status. For participants in Gauteng the State was seen as playing a critical role in this regard.

\section{By way of conclusion}

Themes that emerged from the discussions relate to the complexity of attitudes towards foreigners who are predominantly indigenous African by descent. Informal settlement residents define their identity in relation to their position to the mainstream urban setting. Just like foreigners that live among them, they eke a living in a space of deprivation and on the fringes of urban affluence. Ideologically, they perceive themselves as connected to foreigners by kinship ties and living in close proximity to one another. Foreigners are their neighbours, siblings and relatives.

For some informal residents foreigners pose no threat and are in fact kith and kin; they also extend credit that would otherwise be unavailable. Yet foreigners are also considered disrespectful, untrustworthy and unreliable and even regarded as criminals. Paradoxically attitudes towards foreigners have at different flashpoints been characterised by hostility, as demonstrated by the 2008 and 2015 xenophobic attacks. It is in this context that this study suggests that attitudes are more complex and various aspects intersect with gender to shape changing or dynamic circumstances.

Unlike previous studies (Landau, 2008, 2011; Pillay, 2008; Sharp, 2008; Solomon and Kosaki, 2013; Adjai and Lazaridis, 2013; Dodson, 2010; Neocosmos, 2008) that focus on one aspect or another, this study suggests that the canvas reflects a more complex kaleidoscope where various factors intersect and are interdependent. For example, immigrant entrepreneurs are portrayed as ruthless individuals who deploy a variety of strategies to gain a share of the market in informal settlements. Among these strategies are provision of credit to customers for extended periods in order to poach and retain them, checking the debt status of potential customers before selling to them, reducing prices and putting competitors out of business. This attitude can be distinguished from those towards foreigners in waged employment. Whereas employers call for labour deregulation, workers demand tighter controls to protect their jobs, leaving the State in the unenviable position of trying to reconcile disparate interests. Local workers may see immigrant workers as undermining the class struggle against employers, hence the building up of resentment and hostility, while also suspecting that foreigners use surreptitious methods to retain employment at times of retrenchment. Focus groups in KZN expressed these views, partially explaining why attacks were directed at foreigners.

Given the colonial history of SA where violence is often a way of settling disagreements and conflicts, our findings reflect the extent to 
which the intersection of gender, class, race, ethnicity and many factors besides shape different attitudes towards foreigners in SA. While violence is constitutive of processes of difference, it must also be noted that social relations cannot be legislated.

In addition, any policies that deal with attitudes towards foreigners need to take account of identity politics, the gendered dimension vis a vis power structures, class and the social and economic dimensions, all of which have political consequences. As a theoretical tool, intersectionality helps us to explore and illuminate the complexity of attitudes towards foreigners in SA, explicating contestation around resources and intersection of gender, class, race, space and other variables.

\section{References}

Adjai C and Lazaridis G (2013) 'Migration, xenophobia and new racism in post-apartheid South Africa', in International Journal of Social Science Studies, 1 , 1, 192-205.

Ahmed S (2014) The Cultural Politics of Emotion, Edinburgh: Edinburgh University Press.

Alcoff LM (2006) Visible Identities: Race, Gender, and the Self, Oxford: Oxford University Press.

Amin A and Thrift N (2002) Cities: Reimagining the Urban, Cambridge: Polity Press.

Amisi BB (2009) 'Between home's rock and South Africa's hard place: Non-nationals' experiences, livelihood strategies, and choice to remain in post-2008 South Africa', in Synopsis: Policy Studies Bulletin of the Cenre for Policy Studies, 10, 3, 15-21.

Anthias $F$ (2012) 'Hierarchies of social location, class and intersectionality: Towards a translocational frame', in International Sociology, 28, 1, 121-138.

Bastia T (2014) 'Intersectionality, migration and development', in Progress in Development Studies, 14, 3, 237-248.

Bond P, Amisi B, Cele N and Ngwane T (2011) 'Xenophobia and civil society', in Politikon, 38, 1, 59-83.

Cameron J and Ndhlovu TP (2001) 'The comparative economics of EU 'subsidiarity': Lessons from development/regional economic debates', in International Journal of Urban and Regional Research, 25, 2, 327-345.

Collins PH (1998) 'The tie that binds: race, gender, and US violence', in Ethnic and Racial Studies, 21, 5 , 917-938.

Collins PH (2000) Black Feminist Thought: Knowledge, Consciousness, and the Politics of Empowerment, London: Routledge.

Crenshaw KW (1989) 'Demarginalizing the intersection of race and sex: a black feminist critique of antidiscrimination doctrine, feminist theory and antiracist politics', University of Chicago Legal Forum, issue 1, 130d9-167.
Crenshaw KW (1991) 'Mapping the margins: Intersectionality, identity politics, and violence against women of color', in Stanford Law Review, 43, 6, 1241-1299.

Crush J and Ramachandran S (2014) 'Xenophobic violence in South Africa: Denials, minimalism, realism, casual factors and implications', in Migration Policy Series, 66, 1-44.

Davis K (2008) 'Intersectionality as buzzword: A sociology of science perspective on what makes a feminist theory successful', in Feminist Theory, $9,1,67-85$.

Davis M (2004) 'Planet slums: Urban involution and the informal proletariat', in New Left Review, 26 (March-April), 5-34.

Department of Human Settlements (2009) The National Housing Code, Pretoria: Department of Human Settlements.

Dodson B (2010) 'Locating Xenophobia: Debate, discourse, and everyday experience in Cape Town, South Africa', in Africa Today, 56, 3, 2-22.

Harris B (2002) 'Xenophobia: A new pathology for a new South Africa', in D Hook and G Eagle (eds), Psychopathology and Social Prejudice, Cape Town: University of Cape Town Press.

Hendrickse R (2009) 'Xenophobia in South Africa: A domestic dilemma or global discontent?' Paper presented at the XXI IPSA World Congress of Political Sciences, 12-16 July, Universidad De Chile, Santiago.

Hickel J (2014) 'Xenophobia in South Africa: order, chaos, and the moral economy of witchcraft', in Cultural Anthropology, 29, 1, 103-127.

Hlubi P (2015) 'Soweto teen killed in wave of violence. Johannesburg: eNCA', available at: http://www. enca.com/south-africa/soweto-teen-killed-waveviolence, site accessed April 24, 2016.

Hobsbawm E (1992) 'Ethnicity and nationalism in Europe today', in Anthropology Today, 8, 1, 3-8.

Landau LB (2008) 'The meaning of living in South Africa: Violence, condemnation and community after 5-1?, in Migration Studies Working Paper Series, 39, 1-6.

Landau LB (2011) 'Demons and democracy: Positive values and the politics of outsiderness in contemporary South Africa', in Loren B Landau (ed), Exorcising the Demons Within: Xenophobia, Violence and Statecraft in Contemporary South Africa, Johannesburg: Wits University Press.

Landau LB, Ramjathan-Keogh K and Singh G (2005) 'Xenophobia in South Africa and problems related to it', in Forced Migration Working Paper Series 13, 1-41.

Maluleke T (2015) 'Xenophobic denial of xenophobia', Sunday Independent, 1 February, available at: http://www.iol.co.za/sundayindependent/ xenophobic-denial-of-xenophobia, site accessed April 23, 2016.

McConnell C (2009) 'Migration and xenophobia in South Africa', in Conflict Trends, 1, 34-40.

Misago JP (2009) 'Xenophobic violence in South Africa: Reflection on casual factors and implications', in Synopsis: Policy Studies Bulletin of the Centre for Policy Studies, 10, 3, 3-8.

Morris A (1998) '“Our Fellow Africans make our lives hell": The lives of Congolese and Nigerians 
living in Johannesburg', in Ethnic and Racial Studies, 21, 6, 1116-1136.

Msimang S (2014) 'Belonging - Why South Africans refuse to let Africa in', in Africa is a Country, available at: http://africasacountry.com/2014/04/ belonging-why-south-africans-refuse-to-letafrica-in/, site accessed April 15, 2016.

Mupotsa D (2011) 'From Nation to Family: Researching Gender and Sexuality', in Researching Violence in Africa: Ethical and Methodological Challenge, 6, 95-110.

Ndhlovu TP (2012) 'Globalisation: A theoretical reflection', in World Journal of Entrepreneurship, Management and Sustainable Development, 8 , 2, 95-112.

Ndhlovu TP (2016a). 'Colonialsm and the economics of unequal exchange', in B Avari and GG Joseph (eds), Interwoven World: Ideas and Encounters in History, Chicago: Common Ground Publishing LLC, University of Illinois, USA.

Ndhlovu TP (forthcoming 2016b) 'Elusive Solutions to Poverty and Inequality: From "Trickle Down" to "Solidarity Economy"', in B Mpofu and SJ Ndlovu-Gatsheni (eds), Making Sense of Development, Inequality and Poverty in subSaharan Africa after the 2008 Global Financial Crisis, Pretoria: AMRI Book Series, South Africa.

Ndhlovu TP and Khalema NE (2015) 'Southern Africa', in V Barnett (ed), The Routledge Handbook to the History of Global Economic Thought, London: Routledge.

Ndhlovu TP and Spring A (2009) 'South African women in business and management: transformation in progress', in Journal of African Business, $10,31-49$.

Ndinda C, Chimbwete C, McGrath N and Pool R (2008) 'Perceptions of anal sex in rural South Africa', in Culture Health and Sexuality, 12, 2, 205-121.

Ndinda C and Okeke-Uzodike U (2012) 'Present but absent: women in business leadership in South Africa', in Journal of International Women's Studies, 13, 1, 127-145.

Ndinda C, Chimbwete C, McGrath N, Pool R (2007a) 'Community perceptions towards people living with HIV/AIDS in rural KwaZulu-Natal', in AIDS Care, 19, 1, 92-101.

Ndinda C, Okeke-Uzodike U, Chimbwete C and Pool R (2007b) 'Gender relations in the context of HIV/ AIDS in rural South Africa', in AIDS Care 19, 7 , 844-849.

Ndinda C, Hongoro C, Labadarios D, et al (2016) Baseline Assessment for future impact evaluation of informal settlements targeted for upgrading, Pretoria: Human Science Research Council. Technical Report Commissioned by the National Department of Human Settlements, South Africa. Neocosmos M (2008) 'The politics of fear and the fear of politics', in Journal of Asian and African Studies, 43, 6, 586-594.

Nyamnjoh FB (2006) 'Mobility, citizenship and xenophobia in South Africa', in Francis B Nyamnjoh (ed), Insiders and Outsiders: Citizenship and Xenophobia in Contemporary Southern Africa, Dakar: Codesria Books and Zed Books.

Nyamnjoh FB (2007) 'From bounded to flexible citizenship: Lessons from Africa', in Citizenship Studies, 11, 1, 73-82.

Olifant N (2015) 'Foreigners want plan for their safety', in Times Live, available at: http://www.timeslive. co.za/thetimes/2015/04/08/foreigners-want-planfor-their-safety, site accessed April 23, 2016.

Pillay S (2008) '“Fortress SA"? A Response to John Sharp', in Anthropology Today, 24, 5, 22.

Rao V (2006). 'Review Essay: Slum as theory: The South/Asian city and globalisation', in International Journal of Urban and Regional Research, 30, 1, 225-232.

Reitzes M (2009) 'Xenophobic triggers situated in the history and legal provisions of domestic and international policies in South Africa', in Synopsis: Policy Studies Bulletin of the Centre for Policy Studies, 10, 3, 9-15.

Rivas C (2012) 'Coding and analysing qualitative data' in C Searle (ed), Researching Society and Culture, 3rd edn, Sage, London, pp 366-392.

Searle C (ed) (2012). Researching Society and Culture, 3rd edn, London: Sage.

Shahrokh T (2015) 'Towards more inclusive strategies to address gender-based violence', in IDS Policy Briefing, 104, November.

Sharp J (2008) '“Fortress SA"? John Sharp responds', in Anthropology Today, 24, 5, 22.

Solomon $\mathrm{H}$ and Kosaka $\mathrm{H}$ (2013) 'Xenophobia in South Africa: Reflections, narratives and recommendations', in Southern African Peace and Security Studies, 2, 2, 5-30.

Tshitereke C (1999) 'Xenophobia and relative deprivation', Crossings, 3, 2, 4-5.

UN Habitat (2010) State of African cities, Nairobi: United Nations Habitat.

Walby, S. (2007). 'Complexity Theory, Systems Theory, and Multipple Intersecting Social Inequalities', in Philosophy of the Social Sciences, $37,4,449-470$. 


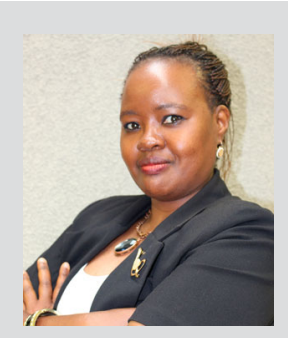

CATHERINE NDINDA is a Chief Research Specialist at the Economic Performance and Development unit of the Human Sciences Research Council (HSRC). She holds a PhD in Social Science and an MSc in Urban and Regional Planning (Development Studies), with extensive experience in the design and implementation of Social Science research and evaluation of the effectiveness of national policies. Her current interests are in monitoring and evaluation, and she has conducted and contributed to evaluation studies, including 'Design assessment of the South African Indigenous Knowledge Systems (IKS) Policy' (principal investigator); 'South Africa's Revitalized Response to AIDS and HIV' (SARRAH) (expert evaluator), 'Audit Survey of the Housing Association of Blaauwberg' (HAB) (principal investigator) and 'Baseline Assessment for the Future Impact Evaluation of Informal Settlements Targeted for Upgrading' (2014-2016) (principal investigator). In population and health Catherine has been involved in studies including 'An exploratory study into the nature and extent of Substance Abuse in Mpumalanga' (2012)(co-principal investigator), 'Circular Migration in Eastern Cape' (2013) and 'Situation analysis of Population and Development in Eight Priority Districts in Eastern Cape and KZN' (2013).

Catherine has been involved in policy development and policy analysis and she currently holds a research fellowship on 'The analysis of non-communicable disease policies in SA'. Given her research in analysing the post-apartheid housing policy, she has published widely on subsidised housing in SA and gender. She is author of the book Women and Subsidised housing in KwaZuluNatal published by Lambert Publishing (2011), and co-authored a text on Women's Activism for Gender Equality in Africa. Her work has appeared in high impact development and gender studies journals. Email: cndinda@hsrc.ac.za

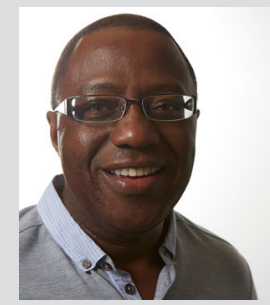

TIDINGS P. NDHLOVU obtained his PhD from the University of East Anglia in the UK, and is a Senior Lecturer in Economics in the Department of Accounting, Finance and Economics at Manchester Metropolitan University, UK, having previously taught at the University of Manchester, UMIST (now part of the University of Manchester), University of East Anglia and the University of Essex. He is also a Visiting Research Fellow at the Graduate School of Business Leadership (GSBL), University of South Africa, Nanjing University, China, and the University of Caen, France. Tidings is also external examiner (postgraduate programmes) at the University of Fort Hare, SA, and supervises PhD candidates at the Uganda Management Institute, Durban University of Technology and GSBL in SA.

He was involved in founding the International Academy of African Business and Development (IAABD) 16 years ago, including the organisation's journal, The Journal of African Business. He has been Executive Secretary of IAABD for the last 3 years. He has also been Associate Editor of the Journal of Green Economy and Development (JGED) since its inception in 2014, and chair of the annual JGED Conferences.

Tiding's research focuses on commodity agreements, such as the EU/African, Caribbean and Pacific (ACP) Sugar Protocol, the EU's Common Agricultural Policy and subsidiary questions, the impact of EU aid programmes on developing countries, and theoretical Marxian and Keynesian/neo-Ricardian issues. In addition, he has worked on issues of development, including globalisation, global (financial) crises, structural adjustment policies, foreign direct investment, and Intensive Alternatives to Custody (UK), entrepreneurship, food 'crisis', sustainable development and service delivery, corporate social responsibility and corporate social investment, decent work and livelihoods strategies, and development of crafts for export, particularly with reference to SA. He has visited SA numerous times during 2005-2015 to conduct interviews and initiate joint research projects and/or collaboration with colleagues and institutions in SA. Email: t.ndhlovu@mmu.ac.uk 